\title{
Waiting Time Screening in Diagnostic Medical Imaging - A Case-Based View
}

\author{
Marisa Esteves ${ }^{1}$, Henrique Vicente ${ }^{2,3}$, Sabino Gomes ${ }^{1}$, \\ António Abelha ${ }^{3}$, M. Filipe Santos ${ }^{4}$, José Machado ${ }^{3}$, João Neves ${ }^{5}$, \\ and José Neves ${ }^{3(\bowtie)}$ \\ ${ }^{1}$ Departamento de Informática, Universidade do Minho, Braga, Portugal \\ marisa.araujo.esteves@gmail.com, \\ sabinogomes.antonio@gmail.com \\ 2 Departamento de Química, Escola de Ciências e Tecnologia, \\ Universidade de Évora, Évora, Portugal \\ hvicente@uevora.pt \\ ${ }^{3}$ Centro Algoritmi, Universidade do Minho, Braga, Portugal \\ \{abelha, jmac, jneves\}@di.uminho.pt \\ ${ }^{4}$ Centro Algoritmi, Universidade do Minho, Guimarães, Portugal \\ mfs@dsi.uminho.pt \\ 5 Drs. Nicolas \& Asp, Dubai, United Arab Emirates \\ joaocpneves@gmail.com
}

\begin{abstract}
Due to the high standards expected from diagnostic medical imaging, the analysis of information regarding waiting lists via different information systems is of utmost importance. Such analysis, on the one hand, may improve the diagnostic quality and, on the other hand, may lead to the reduction of waiting times, with the concomitant increase of the quality of services and the reduction of the inherent financial costs. Hence, the purpose of this study is to assess the waiting time in the delivery of diagnostic medical imaging services, like computed tomography and magnetic resonance imaging. Thereby, this work is focused on the development of a decision support system to assess waiting times in diagnostic medical imaging with recourse to operational data of selected attributes extracted from distinct information systems. The computational framework is built on top of a Logic Programming Case-base Reasoning approach to Knowledge Representation and Reasoning that caters for the handling of incomplete, unknown, or even self-contradictory information.
\end{abstract}

Keywords: Waiting time - Diagnostic medical imaging - Knowledge representation and reasoning - Logic programming - Case-based reasoning • Similarity analysis 